\title{
NeuroRegulation
}

\section{Editorial - Volume 4, Number 3-4}

Citation: Cannon, R. L. (2017). Editorial - Volume 4, Number 3-4. NeuroRegulation, 4(3-4), 101. http://dx.doi.org/10.15540/nr.4.3-4.101

Copyright: (c) 2017. Cannon. This is an Open Access article distributed under the terms of the Creative Commons Attribution License (CC-BY).
*Address correspondence to: Rex L. Cannon, PhD, BCN, Knoxville Neurofeedback Group, 7147 Kingston Pike, Ste 103, Knoxville, TN 37919, USA. Email: rcannonphd@gmail.com
Welcome to NeuroRegulation Volume 4, Issue 3-4.

We wish to thank all students, researchers, and clinicians that submitted and presented at this year's annual conference in Connecticut. It was a pleasure to hear the presentations, and we encourage presenters to submit their data to NeuroRegulation.

In the current issue authors utilize a variety of novel techniques and report interesting findings. Erik Peper and Richard Harvey discuss the implications of indirect treatment effects in placebo-controlled clinical trials. Connie McReynolds, Jodi Bell, and Tina Lincourt discuss data concerning neurofeedback techniques in veterans with posttraumatic stress disorder (PTSD). Mark Zinn, Marcie Zinn, and Leonard Jason present data examining small-world analytics of EEG connectivity in Chronic Fatigue Syndrome (CFS). Finally, we provide selected abstracts from the proceedings of the 2017 conference for the International Society for Neurofeedback and Research (ISNR).
NeuroRegulation thanks these authors for their valuable contributions to the scientific literature for neurofeedback and quantitative EEG. We strive for high quality and interesting empirical topics. We encourage the members of ISNR and other biofeedback and neuroscience disciplines to consider publishing with us. It is important to stress that publication of case reports is always useful in furthering the advancement of an intervention for both clinical and normative functioning. Thus, we encourage all individuals practicing neurofeedback to submit case studies! We thank you for reading NeuroRegulation!

Rex L. Cannon, PhD, BCN

Editor-in-Chief

Email: rcannonphd@gmail.com

Published: December 8, 2017 